\title{
Vocabulário expressivo e consciência fonológica: correlações destas variáveis em crianças com desvio fonológico
}

\author{
Expressive vocabulary and phonological awareness: \\ correlations in children with phonological disorders
}

\author{
Tassiana Isabel Kaminski ${ }^{1}$, Helena Bolli Mota², Carla Aparecida Cielo²
}

\begin{abstract}
RESUMO
Objetivo: Investigar a correlação entre o desempenho de crianças com desvio fonológico em vocabulário expressivo e consciência fonológica e analisar a influência da idade. Métodos: Contou-se com amostra de 24 crianças entre 5 e 7 anos, diagnosticadas com desvio fonológico e divididas em três grupos, de acordo com a faixa etária. Os sujeitos realizaram foram avaliados com relação às habilidades de consciência fonológica e vocabulário expressivo. Os dados dos grupos receberam análise estatística para verificar a correlação entre os desempenhos dos dois testes e comparar as variáveis numéricas entre as faixas etárias. Resultados: No grupo de 5 anos, observou-se 18 correlações significativas entre as subtarefas em consciência fonológica e os campos de vocabulário expressivo. Destas, 17 foram positivas e uma negativa. Na idade de 6 anos, verificou-se dez correlações, nove foram positivas e uma negativa. No grupo de 7 anos, 11 correlações foram observadas, das quais seis foram negativas e cinco positivas. Ao analisar as idades, em ambos os testes, maiores escores foram obtidos pelos sujeitos com maior idade. Conclusão: Houve correlação entre algumas habilidades de consciência fonológica e o vocabulário expressivo dos sujeitos deste estudo, nas diferentes idades. O desempenho em ambas as provas melhorou com o aumento da idade.
\end{abstract}

Descritores: Testes de linguagem; Vocabulário; Semântica; Linguagem infantil; Desenvolvimento da linguagem; Criança

\section{INTRODUÇÃO}

Crianças que apresentam anormalidades em seu desenvolvimento fonológico, na ausência de uma etiologia orgânica aparente, são diagnosticadas como portadoras de desvios fonológicos. Suas dificuldades estão no nível de organização do sistema fonológico, e não de problema articulatório ${ }^{(1)}$. Embora possam ter um inventário fonético relativamente completo, apresentam dificuldades em utilizar estes sons para corresponder aos da palavra-alvo ${ }^{(2)}$.

A linguagem compreende cinco subsistemas: pragmático, semântico, sintático, morfológico e fonológico. O fonológico refere-se ao modo de organização e funcionamento dos sons na

Trabalho realizado no Centro de Estudos de Linguagem e Fala (CELF) do Curso de Fonoaudiologia, Universidade Federal de Santa Maria - UFSM Santa Maria (RS), Brasil.

(1) Programa de Pós-graduação (Mestrado) em Distúrbios da Comunicação Humana, Universidade Federal de Santa Maria - UFSM - Santa Maria (RS), Brasil.

(2) Curso de Fonoaudiologia e Programa de Pós-Graduação em Distúrbios da Comunicação Humana, Universidade Federal de Santa Maria - UFSM Santa Maria (RS), Brasil.

Endereço para correspondência: Tassiana Isabel Kaminski. R. Clemente Soltis, 67, Guarani das Missões (RS), Brasil, CEP: 97950-000. E-mail: tassikaminski@yahoo.com.br

Recebido em: 8/3/2010; Aceito em: 31/8/2010 língua. Dada a inter-relação entre os subsistemas linguísticos, alterações de fala, como os desvios fonológicos, devem ser consideradas problemas de linguagem e o tratamento deve incluir os demais aspectos linguísticos ${ }^{(3)}$, quando estes também estiverem alterados.

A consciência fonológica pode ser definida como a habilidade do ser humano de pensar conscientemente sobre os sons da fala e, através dela, poder refletir sobre, julgar e manipular as estruturas sonoras das palavras ${ }^{(4)}$.

O surgimento e consolidação dos diferentes tipos de habilidades em consciência fonológica apresenta uma sequência, iniciando com as habilidades em consciência de palavras, seguida pela de rimas, depois de sílabas e, por último, de fonemas ${ }^{(5)}$.

Com o aumento da idade e do contato com a linguagem escrita, ocorre uma melhora no desempenho das habilidades em consciência fonológica ${ }^{(5)}$.

Nem todas as crianças podem ser capazes de realizar com êxito as tarefas de consciência fonológica, principalmente na presença de condições patológicas. Um estudo ${ }^{(6)}$ comparando o desempenho de crianças com desenvolvimento típico de fala e crianças com desvio fonológico, entre quatro e oito anos, verificou que os sujeitos com desvio fonológico mostraram pior desempenho do que os outros sujeitos.

Para alguns autores ${ }^{(7)}$, crianças com desvio fonológico seriam consideradas de risco para futuras dificuldades no de- 
senvolvimento da linguagem, e deveriam ser estimuladas em habilidades de consciência fonológica. Adicionalmente, um estudo ${ }^{(8)}$ concluiu que a melhora nas habilidades em consciência fonológica favorece o desenvolvimento do sistema fonológico, permitindo que a criança fique mais atenta em relação aos sons da fala e perceba a importância da presença dos traços que se encontram comprometidos na sua fala.

Em relação ao vocabulário, em torno de um ano de idade, as crianças produzem suas primeiras palavras. $\mathrm{O}$ vocabulário produtivo aumenta devagar no início, mas durante o segundo ano de vida, entre um ano e seis meses e um ano e oito meses, ocorre uma "explosão" no vocabulário, em que muitas palavras são adquiridas ${ }^{(9)}$.

Diversos estudos ${ }^{(9-13)}$ relacionaram o desenvolvimento do vocabulário ao aumento da idade, tanto em crianças com aquisição típica de fala quanto com desvio fonológico.

A aquisição de novas palavras aprimora o sistema e torna a criança capaz de aprender mais palavras. O desenvolvimento do vocabulário pode ser conceituado como um processo contínuo que permite ao sistema lexical aprimorar a acessibilidade às informações ${ }^{(14)}$.

Elaborar o estoque de palavras que forma a linguagem inclui uma série de processos complexos: a criança precisa adquirir a característica fonológica das palavras, seus significados, e também suas categorias sintáticas bem como as propriedades de cada uma dessas classes ${ }^{(9)}$.

Se o sistema fonológico da criança é limitado e os sons restritos a certas classes e posições, isso pode influenciar o desenvolvimento lexical ${ }^{(15)}$. Com o uso de palavras homônimas, em função de desvios fonológicos, a fala de uma criança pode ficar mais difícil de ser compreendida. Isso ocorre porque a criança produz a mesma palavra para denominar diferentes objetos, uma vez que possui poucos fonemas à disposição ${ }^{(2)}$.

Estudos sugerem que há uma relação entre o campo fonológico (a consciência fonológica e a precisão de fala) e o léxico ${ }^{(16)}$. Não é possível afirmar ainda qual a influência que um exerce sobre o outro, ou se esta influência ocorre de forma mútua. A literatura da área refere que a aquisição de alguns subsistemas linguísticos como o sintático, morfológico e fonológico relaciona-se, durante o desenvolvimento da linguagem, com o aprendizado das palavras e seu uso adequado ${ }^{(11)}$.

Apesar de os desvios fonológicos representarem alteração no nível fonológico do sujeito ${ }^{(1,2)}$, acredita-se que alterações em outros subsistemas linguísticos podem ocorrer nesse quadro. Em virtude de poucos estudos terem sido realizados para identificar outros subsistemas da linguagem defasados nos casos de desvio fonológico, além da fonologia, esta pesquisa procura entender a relação entre fonologia e léxico.

O objetivo desta pesquisa foi correlacionar o desempenho de crianças com desvio fonológico em testes de vocabulário expressivo e de consciência fonológica e a influência da idade.

\section{MÉTODOS}

Esta pesquisa se configura como um estudo de campo, não-experimental, exploratório, transversal e quantitativo.

O presente estudo faz parte de dados clínicos de dois projetos de pesquisa aprovados pelo Comitê de Ética em
Pesquisa (CEP) da Universidade Federal de Santa Maria (UFSM) sob registros de números 0102.0.243.000-07 e 0103.0.243.000-07.

Todos os sujeitos envolvidos foram autorizados por seus pais/responsáveis através da assinatura do Termo de Consentimento Livre e Esclarecido (TCLE). Este termo informa sobre os objetivos da pesquisa, a justificativa, os procedimentos a serem adotados, riscos, benefícios, sigilo dos dados coletados, garantia de esclarecimento e liberdade de recusar a participar em qualquer momento. A assinatura desse documento, de livre vontade, é uma condição para a participação da criança na pesquisa, mantendo-se a possibilidade de desistência quando conveniente. Além da assinatura do TCLE, a criança deveria assentir sua participação na pesquisa.

A coleta dos dados ocorreu no período de outubro de 2007 a dezembro de 2008. Foi realizada no Centro de Estudos de Linguagem e Fala (CELF), serviço público de atendimento fonoaudiológico vinculado à UFSM, e em duas escolas públicas e uma escola filantrópica de ensino fundamental, para obter amostra com um número maior de sujeitos. Os sujeitos envolvidos estavam escolarizados, fazendo parte de turmas de educação infantil e de primeira série (alfabetização).

Os procedimentos de seleção da amostra e coleta de dados foram realizados por mestrandos e acadêmicos bolsistas de iniciação científica dos $7^{\circ}$ e $8^{\circ}$ semestres da UFSM.

No CELF, os sujeitos foram selecionados por meio das triagens do Setor de Fala da instituição. Nas escolas, com todas as crianças autorizadas através do TCLE, foi realizada triagem fonoaudiológica. Essa triagem constou de avaliações do sistema estomatognático, dos sistemas fonológico e fonético, de linguagem e triagem auditiva.

Foram critérios de inclusão a autorização dos pais e/ou responsáveis; a criança assentir sua participação; ter idade entre 5 e 7 anos e apresentar desvio fonológico. Os critérios de exclusão foram apresentar alterações psicológicas, cognitivas e neurológicas evidentes à observação, pelo pesquisador; não apresentar resultados normais na triagem fonoaudiológica quanto ao sistema estomatognático, fonético, compreensão e/ ou expressão da linguagem, e triagem auditiva e ter realizado ou realizar tratamento fonoaudiológico.

A triagem teve o objetivo de selecionar crianças que apresentavam alterações apenas na fala, excluindo-se qualquer outra alteração. Para realizar o diagnóstico de desvio fonológico, foram utilizadas as figuras propostas na Avaliação Fonológica da Criança $(\mathrm{AFC})^{(1)}$.

As crianças que não passaram por um ou mais critérios de avaliação foram excluídas da amostra e encaminhadas para os procedimentos necessários, como, por exemplo, consulta com médico otorrinolaringologista, avaliação odontológica, terapia fonoaudiológica, entre outros. Desta forma, os sujeitos que não se enquadravam nos critérios de inclusão, a partir da avaliação, foram excluídos.

O grupo de estudo, formado tanto pelas crianças das escolas quanto do serviço público, incluiu 24 crianças, com idade compreendida entre 5 anos e 3 dias e 7 anos, 10 meses e 29 dias, com desvio fonológico e de ambos os gêneros ( 15 meninos e nove meninas). Esses sujeitos foram divididos em três grupos, conforme sua faixa etária, compondo um grupo 
para as crianças de 5 anos, com dez sujeitos (sete meninos e três meninas), outro para as de 6 anos, com dez sujeitos (cinco meninos e cinco meninas), e um grupo para as de 7 anos, com quatro sujeitos (três meninos e uma menina). Optou-se em dividir a amostra de acordo com a idade porque os testes utilizados para a coleta de dados separam os sujeitos por faixa etária, para classificar o seu desempenho. Esse critério possibilitou a comparação dos achados desta pesquisa com as referências dos testes utilizados.

Para iniciar o processo de coleta de dados, essas crianças foram submetidas à avaliação do vocabulário expressivo, através da prova de verificação do vocabulário do teste $\mathrm{ABFW}^{(17)}$, e à avaliação da consciência fonológica, através do protocolo de avaliação das habilidades de consciência fonológica $(\mathrm{PTCF})^{(18,19)}$. Estas avaliações foram realizadas em dois dias distintos para cada criança, com sessões de, em média, 30 minutos de duração. No primeiro dia realizou-se a avaliação de consciência fonológica e os sujeitos realizaram as subtarefas até demonstrarem cansaço; nesse caso, a aplicação do teste era suspensa e retomada em outro dia. No segundo dia, as crianças terminaram as tarefas restantes em consciência fonológica e nomearam as figuras do teste de vocabulário expressivo.

Por meio da prova de verificação do vocabulário do teste $\mathrm{ABFW}^{(17)}$ avaliou-se o vocabulário expressivo. Esse instrumento é composto por 118 figuras classificadas em nove campos conceituais: vestuário, animais, alimentos, meios de transporte, móveis e utensílios domésticos, profissões, locais, formas e cores, brinquedos e instrumentos musicais. As respostas das crianças foram registradas e analisadas como designações por vocábulos usuais, não-designações e processos de substituições. Para este estudo, consideraram-se apenas as designações por vocábulos usuais em cada campo conceitual.

Para a avaliação da consciência fonológica, foi utilizado o protocolo de avaliação das habilidades de consciência fonológica (PTCF) ${ }^{(18,19)}$, aplicando-se apenas as tarefas propostas para as faixas etárias de 5, 6 e 7 anos de idade, pois, segundo o teste, estas são as subtarefas nas quais estes sujeitos apresentam desempenho adequado à sua faixa etária. As subtarefas são: segmentação de frases de duas palavras (T1_2 palavras) aplicada para os sujeitos de 5, 6 e 7 anos; segmentação de frases de três palavras (T1_3 palavras) para as idades de 5 e 7 anos; segmentação de frases de quatro palavras (T1_4 palavras) para as idades de 5 e 7 anos; segmentação de frases de cinco palavras (T1_5 palavras) para a idade de 7 anos; segmentação de frases de seis palavras (T1_6 palavras) para a idade de 7 anos; e segmentação de frases de sete palavras (T1_7 palavras) para a idade de 7 anos.

Também foram aplicadas subtarefas como: realismo nominal (T2) para as idades de 5, 6 e 7 anos; detecção de rimas em palavras dissílabas (T3 dissílabas) para as idades de 5, 6 e 7 anos; e detecção de rimas em palavras trissílabas (T3 trissílabas) para as idades de 5, 6 e 7 anos.

As subtarefas silábicas corresponderam à síntese silábica em palavras dissílabas (T4 dissílabas) para as idades de 5, 6 e 7 anos; síntese silábica em palavras trissílabas (T4 trissílabas) para as idades de 5, 6 e 7 anos; síntese silábica em palavras quadrissílabas (T4 quadrissílabas) para as idades de 5, 6 e 7 anos; segmentação silábica em palavras dissílabas (T5 dissí- labas) para as idades de 5, 6 e 7 anos; segmentação silábica em palavras trissílabas (T5 trissílabas) para as idades de 5, 6 e 7 anos; segmentação silábica em palavras quadrissílabas (T5 quadrissílabas) para as idades de 5, 6 e 7 anos; detecção de sílaba em palavras com sílabas iguais em posição inicial (T6 inicial) para as idades de 5, 6 e 7 anos; detecção de sílaba em palavras com sílabas iguais em posição final (T6 final) para as idades de 5, 6 e 7 anos; detecção de sílaba em palavras com sílabas iguais em posição medial (T6 medial) para as idades de 5, 6 e 7 anos; reversão silábica em palavras dissílabas (T7 dissílabas) para as idades de 6 e 7 anos; reversão silábica em palavras trissílabas (T7 trissílabas) para a idade de 7 anos; e reversão silábica em palavras quadrissílabas (T7 quadrissílabas) para a idade de 7 anos.

As subtarefas fonêmicas englobaram: exclusão de fonema em início de palavra (T8 inicial) para a idade de 7 anos; exclusão de fonema no meio de palavra (T8 medial) para a idade de 7 anos; exclusão de fonema em final de palavra (T8 final) para a idade de 7 anos; detecção de fonemas em palavras com fonemas iguais na posição inicial (T9 inicial) para as idades de 5, 6 e 7 anos; detecção de fonemas em palavras com fonemas iguais na posição final (T9 final) para as idades de 6 e 7 anos; detecção de fonemas em palavras com fonemas iguais na posição medial (T9 medial) para a idade de 7 anos; síntese fonêmica em palavras de três fonemas (T10_3 fonemas) para a idade de 7 anos; síntese fonêmica em palavras de quatro fonemas (T10_4 fonemas) para a idade de 7 anos; síntese fonêmica em palavras de cinco fonemas (T10_5 fonemas) para a idade de 7 anos; síntese fonêmica em palavras de seis fonemas (T10_6 fonemas) para a idade de 7 anos; segmentação fonêmica em palavras de três fonemas (T11_3 fonemas) para a idade de 7 anos; segmentação fonêmica em palavras de quatro fonemas (T11_4 fonemas) para a idade de 7 anos; segmentação fonêmica em palavras de cinco fonemas (T11_5 fonemas) para a idade de 7 anos; e reversão fonêmica em palavras de dois e três fonemas (T12_2 e 3 fonemas) para a idade de 7 anos.

Conforme critério proposto pelo $\mathrm{PTCF}^{(18,19)}$, os pontos computados foram analisados pelos critérios de escores em cada item (dois pontos para a resposta correta na primeira tentativa, um ponto para a resposta correta na segunda tentativa, ou zero se errar nas duas tentativas). Cada subtarefa poderia alcançar um máximo de dez pontos, sem haver somatória dos escores dos subtipos, pois cada um deles representa determinado nível de complexidade dentro da mesma tarefa.

Para possibilitar a análise dos dados e a comparação entre os dois testes utilizados, foi estabelecida nota de 0 a 100 para cada teste. Em cada subtarefa do PTCF, tal nota corresponde à média percentual calculada da seguinte forma: número de pontos obtidos, divididos por dez (número máximo de pontos a serem obtidos em cada subtarefa) e multiplicados por 100. Para cada campo conceitual do teste de vocabulário expressivo, esta nota foi uma porcentagem calculada pelo número de designações por vocábulos usuais utilizadas, dividido pelo número de itens a serem designados em cada campo conceitual e multiplicados por 100.

Foi realizada análise estatística dos resultados do vocabulário expressivo e consciência fonológica nas diferentes idades. A análise de correlação entre os desempenhos dos dois testes foi 
calculada pelo coeficiente de correlação de Spearman, devido à ausência de distribuição normal.

Para comparar as variáveis numéricas entre duas faixas etárias, foi utilizado o teste de Mann-Whitney, e para comparar as variáveis numéricas entre as três faixas etárias, foi utilizado o teste de Kruskal-Wallis, também devido à ausência de distribuição normal. O nível de significância adotado para os testes estatísticos foi de 5\%, ou seja, p<0,05.

\section{RESULTADOS}

Os valores significativos da correlação entre os escores dos campos conceituais de vocabulário expressivo e as subtarefas de consciência fonológica, separadamente, para cada faixa etária, estão apresentados nas Tabelas 1, 2 e 3.

É importante salientar que, na Tabela 3, as correlações de crianças com 7 anos de idade devem ser vistas com limitação, devido ao tamanho reduzido deste grupo (quatro sujeitos). Não foi possível calcular a correlação entre alguns campos conceituais do vocabulário com algumas subtarefas em consciência fonológica porque os quatro sujeitos atingiram a mesma pontuação, ou seja, o desvio-padrão foi zero (Tabela 3).

Para a idade de 5 anos, observou-se 18 correlações significativas entre as subtarefas em consciência fonológica e os campos de vocabulário expressivo (Tabela 1). Destas, 17 foram positivas, ou seja, quanto melhor o desempenho em vocabulário, melhor era o desempenho em consciência fonológica, ou vice-versa. Apenas uma correlação negativa foi observada, entre "vestuário" e detecção de sílaba em início de palavra.

Esses dados mostram que, para a idade de 5 anos, as tarefas que apontaram correlação com vocabulário (campos conceituais "animais", "meios de transporte", profissões", "locais", "formas e cores' e 'brinquedos e instrumentos musicais") foram a segmentação de frases em palavras, realismo nominal, detecção de rimas e síntese silábica. Nas tarefas fonêmicas, ocorreu apenas uma correlação entre detecção de fonemas e "profissões".

Não foram encontradas correlações em: "alimentos"; "móveis e utensílios domésticos"; segmentação de frases de quatro palavras; detecção de rimas em palavras trissílabas; segmentação silábica em palavras dissílabas, trissílabas e quadrissílabas; e a detecção de sílabas em final e meio de palavras.

$\mathrm{Na}$ idade de 6 anos, verificou-se dez correlações entre vocabulário expressivo e consciência fonológica, da quais nove foram positivas e uma negativa (Tabela 2). A correlação negativa foi entre segmentação silábica em palavras trissílabas e "móveis e utensílios domésticos".

Dessa forma, as tarefas de consciência fonológica que apontaram correlação positiva com vocabulário expressivo (campos conceituais "vestuário", "animais", "alimentos", "móveis e utensílios domésticos", "locais" e "formas e cores") para a idade de seis anos foram segmentação de frases de duas palavras, realismo nominal, detecção de rimas em palavras dissílabas e trissílabas, síntese silábica em palavras quadrissílabas, segmentação silábica em palavras dissílabas, reversão silábica em palavras dissílabas, e detecção de fonemas em início e final de palavras.

Não foram encontradas correlações entre a nomeação de "meios de transporte"; "profissões"; "brinquedos e instrumentos musicais"; síntese silábica em palavras dissílabas e trissílabas; segmentação silábica em palavras quadrissílabas; e a detecção de sílabas em início, final e meio de palavras.

Entre os sujeitos com 7 anos foram encontradas 11 correlações, das quais, seis foram negativas e cinco positivas (Tabela

Tabela 1. Valores significativos na análise de correlação entre os desempenhos dos testes de vocabulário e consciência fonológica, para a faixa etária de cinco anos $(n=10)$

\begin{tabular}{|c|c|c|c|c|c|c|c|}
\hline Tarefas & Vestuário & Animais & $\begin{array}{l}\text { Meios de } \\
\text { transporte }\end{array}$ & Profissões & Locais & Formas e cores & $\begin{array}{l}\text { Brinquedos e } \\
\text { instrumentos }\end{array}$ \\
\hline T1_2 palavras & - & $\begin{array}{l}r=0,67110 \\
p=0,0336^{*}\end{array}$ & - & - & $\begin{array}{l}r=0,75657 \\
p=0,0113^{*}\end{array}$ & - & - \\
\hline T1_3 palavras & - & - & - & - & - & $\begin{array}{l}r=0,78705 \\
p=0,0118^{*}\end{array}$ & - \\
\hline T2 & - & $\begin{array}{l}r=0,77492 \\
p=0,0085^{\star}\end{array}$ & $\begin{array}{l}r=0,71430 \\
p=0,0203^{*}\end{array}$ & - & $\begin{array}{l}r=0,79080 \\
p=0,0065^{\star}\end{array}$ & - & - \\
\hline T3 dissílabas & - & $\begin{array}{l}r=0,78127 \\
p=0,0076^{*}\end{array}$ & - & - & $\begin{array}{l}r=0,73363 \\
p=0,0157^{*}\end{array}$ & - & - \\
\hline T4 dissílabas & - & $\begin{array}{l}r=0,81482 \\
p=0,0041^{*}\end{array}$ & - & $\begin{array}{l}r=0,87773 \\
p=0,0008^{*}\end{array}$ & $\begin{array}{l}r=0,77087 \\
p=0,0090^{*}\end{array}$ & $\begin{array}{l}r=0,85465 \\
p=0,0016^{*}\end{array}$ & $\begin{array}{l}r=0,79517 \\
p=0,0060^{\star}\end{array}$ \\
\hline T4 trissílabas & - & - & - & $\begin{array}{l}r=0,77739 \\
p=0,0081^{*}\end{array}$ & - & - & - \\
\hline T4 quadrissílabas & - & $\begin{array}{l}r=0,67011 \\
p=0,0340^{*}\end{array}$ & - & - & - & - & $\begin{array}{l}r=0,76296 \\
p=0,0103^{\star}\end{array}$ \\
\hline T6 inicial & $\begin{array}{l}r=-0,76732 \\
p=0,0096^{\star}\end{array}$ & - & - & - & - & - & - \\
\hline T9 inicial & - & - & - & $\begin{array}{l}r=0,71238 \\
p=0,0208^{*}\end{array}$ & - & - & - \\
\hline
\end{tabular}

*Valores significativos $(\mathrm{p} \leq 0,05)$ - Coeficiente de Correlação de Spearman

Legenda: T1 = segmentação de frases de 2 e 3 palavras; T2 = realismo nominal; T3 = Detecção de rimas em palavras dissílabas; T4 = síntese silábica em palavras dissílabas, trissílabas e quadrissílabas; T6 = detecção de sílabas iguais em início de palavras; T9 = detecção de fonemas iguais em início de palavras; $r$ = coeficiente de correlação de Spearman; $p=$ valor de $p ; n$ = número de sujeitos; - = valores não significativos 
Tabela 2. Valores significativos na análise de correlação entre os desempenhos dos testes de vocabulário e consciência fonológica, para a faixa etária de seis anos $(n=10)$

\begin{tabular}{|c|c|c|c|c|c|c|}
\hline Tarefas & Vestuário & Animais & Alimentos & Móveis e utensílios & Locais & Formas e cores \\
\hline T1_2 palavras & - & - & - & - & $\begin{array}{l}r=0,78573 \\
p=0,0071^{*}\end{array}$ & - \\
\hline T2 & - & - & - & - & - & $\begin{array}{l}r=0,72725 \\
p=0,0172^{*}\end{array}$ \\
\hline T3 dissílabas & - & - & - & - & - & $\begin{array}{l}r=0,68410 \\
p=0,0291^{*}\end{array}$ \\
\hline T3 trissílabas & - & - & $\begin{array}{l}r=0.75253 \\
p=0.0120^{*}\end{array}$ & - & - & - \\
\hline T4 quadrissílabas & - & - & - & $\begin{array}{l}r=0,68957 \\
p=0,0274^{*}\end{array}$ & - & - \\
\hline T5 dissílabas & - & - & - & - & - & $\begin{array}{l}r=0,75591 \\
p=0,0114^{*}\end{array}$ \\
\hline T5 trissílabas & - & - & - & $\begin{array}{l}r=-0,63629 \\
p=0,0479^{*}\end{array}$ & - & - \\
\hline T7 dissílabas & $\begin{array}{l}r=0,89815 \\
p=0,0004^{*}\end{array}$ & - & - & - & - & - \\
\hline T9 inicial & - & $\begin{array}{l}r=0,79412 \\
p=0,0061^{*}\end{array}$ & - & - & - & - \\
\hline T9 final & - & - & - & - & $\begin{array}{l}r=0,79688 \\
p=0,0058^{*}\end{array}$ & - \\
\hline
\end{tabular}

*Valores significativos $(p \leq 0,05)$ - Coeficiente de Correlação de Spearman

Legenda: $\mathrm{T} 1$ = segmentação de frases de 2 palavras; $\mathrm{T} 2$ = realismo nominal; $\mathrm{T} 3$ = detecção de rimas em palavras dissílabas e trissílabas; $\mathrm{T} 4$ = síntese silábica em palavras quadrissílabas; $\mathrm{T5}$ = segmentação silábica em palavras dissílabas e trissílabas; $\mathrm{T} 7$ = reversão silábica em palavras dissílabas; $\mathrm{T} 9$ = detecção de fonemas iguais em início e final de palavras; $r=$ coeficiente de correlação de Spearman; $p=$ valor de $p ; n=$ número de sujeitos; - = valores não significativos

Tabela 3. Valores significativos na análise de correlação entre os desempenhos dos testes de vocabulário e consciência fonológica, para a faixa etária de sete anos $(n=4)$

\begin{tabular}{|c|c|c|c|c|c|}
\hline Tarefas & Vestuário & Animais & Móveis e utensílios & Profissões & $\begin{array}{l}\text { Brinquedos e } \\
\text { instrumentos }\end{array}$ \\
\hline T1_5 palavras & $\begin{array}{l}r=-1,00000 \\
p<0,0001^{*}\end{array}$ & - & - & - & - \\
\hline T1_7 palavras & - & $\begin{array}{l}r=-1,00000 \\
p<0,0001^{*}\end{array}$ & - & - & - \\
\hline T3 dissílabas & $\begin{array}{l}r=-1,00000 \\
p<0,0001^{*}\end{array}$ & - & - & - & - \\
\hline T4 trissílabas & - & - & - & - & $\begin{array}{l}r=-1,00000 \\
p<0,0001^{*}\end{array}$ \\
\hline T4 quadrissílabas & - & - & - & $\begin{array}{l}r=-1,00000 \\
p<0,0001^{*}\end{array}$ & 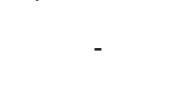 \\
\hline T5 trissílabas & - & - & - & $\begin{array}{l}r=-1,00000 \\
p<0,0001^{*}\end{array}$ & - \\
\hline T7 trissílabas & - & $\begin{array}{l}r=1,00000 \\
p<0,0001^{*}\end{array}$ & - & - & - \\
\hline T10_4 fonemas & - & $\begin{array}{l}r=1,00000 \\
p<0,0001^{*}\end{array}$ & - & - & - \\
\hline T10_5 fonemas & - & $\begin{array}{l}r=1,00000 \\
p<0,0001^{*}\end{array}$ & - & - & - \\
\hline T11_3 fonemas & - & $\begin{array}{l}r=1,00000 \\
p<0,0001^{*}\end{array}$ & - & - & - \\
\hline T12_2 e 3 fonemas & - & - & $\begin{array}{l}r=1,00000 \\
p<0,0001^{*}\end{array}$ & - & - \\
\hline
\end{tabular}

*Valores significativos $(p \leq 0,05)$ - Coeficiente de Correlação de Spearman

Legenda: $r=$ coeficiente de correlação de Spearman; $p=$ valor de $p ; n=$ número de sujeitos; $T 1$ = segmentação de frases de 5 e 7 palavras; T3 = detecção de rimas em palavras dissílabas; $\mathrm{T} 4$ = síntese silábica em palavras trissílabas e quadrissílabas; T5 = segmentação silábica em palavras trissílabas; $T 7$ = reversão silábica em palavras trissílabas; T10 = síntese fonêmica em palavras de 4 e 5 fonemas; T11 = segmentação fonêmica em palavras de 3 fonemas; T12 = reversão fonêmica em palavras de dois e três fonemas; - = valores não significativos 
3). As subtarefas de consciência fonológica que apontaram correlação positiva com vocabulário (com os campos conceituais "animais" e "móveis e utensílios domésticos") foram: reversão silábica de palavras trissílabas, síntese fonêmica em palavras de quatro e cinco fonemas, segmentação fonêmica de palavras de três fonemas e reversão fonêmica de palavras de dois e três fonemas. As correlações negativas ocorreram entre vocabulário (campos conceituais "vestuário", "animais", "profissões" e "brinquedos e instrumentos musicais") e as subtarefas: segmentação de frases de cinco e sete palavras, detecção de rimas em palavras dissílabas, síntese silábica em palavras trissílabas e quadrissílabas, e segmentação silábica em palavras trissílabas.

Não foram encontradas correlações em: "alimentos"; "meios de transporte"; "locais"; "formas e cores"; segmentação de frases de duas, três, quatro e seis palavras; realismo nominal; detecção de rimas em palavras trissílabas; síntese silábica em palavras dissílabas; segmentação silábica em palavras dissílabas e quadrissílabas; detecção silábica em início, final e meio de palavras; reversão silábica em palavras dissílabas e quadrissílabas; exclusão fonêmica em início, final e meio de palavras; detecção fonêmica em início, final e meio de palavras; síntese fonêmica em palavras de três e seis fonemas; e segmentação fonêmica em palavras de quatro e cinco fonemas.

Na Tabela 4, verifica-se a comparação dos desempenhos nos dois testes entre as diferentes idades estudadas. Como o PTCF avalia diferentes tarefas para as diferentes idades, e o número de tarefas aumenta em proporção ao aumento da idade dos sujeitos, algumas subtarefas de consciência fonológica não puderam ser comparadas, pois não foram avaliadas nas outras idades. As tarefas não comparadas entre todas as idades foram: segmentação de frases de três, quatro, cinco, seis e sete palavras; reversão silábica em palavras dissílabas, trissílabas e quadrissílabas; exclusão de fonema em início, meio e final de palavra; detecção de fonemas iguais em final e meio de palavras; síntese fonêmica em palavras de três, quatro, cinco e seis fonemas; segmentação fonêmica em palavras de três, quatro e cinco fonemas; e reversão fonêmica em palavras de dois e três fonemas.

Na Tabela 4, observa-se apenas as diferenças significativas na comparação dos desempenhos entre as três idades estudadas. Encontrou-se diferenças para as três idades nas variáveis: "meios de transporte", realismo nominal, detecção silábica em final de palavra e detecção fonêmica em início de palavra, em que houve diferença entre as idades de 5 e 6 anos e entre 5 e 7 anos, com melhor desempenho das crianças mais velhas. As crianças de 5 anos também mostraram diferença em relação às de sete na nomeação de "móveis e utensílios", "locais" e detecção silábica em início de palavra, com melhor desempenho das de sete anos. Por fim, a diferença entre as crianças de 5 anos e 6 anos foi em segmentação silábica, em palavras trissílabas e quadrissílabas e detecção silábica no meio de palavras, com melhor desempenho das crianças de 6 anos. Não ocorreu diferença entre o desempenho dos sujeitos de 6 e 7 anos. Pelos resultados desta tabela, verifica-se diferença entre idades para alguns dos campos conceituais e para algumas das tarefas em que maiores escores foram obtidos pelos sujeitos com maior idade.

\section{DISCUSSÃO}

Em relação às tarefas fonêmicas, a única comparação que se pode realizar entre a idade dos sujeitos foi na subtarefa de detecção de fonemas em palavras com fonemas iguais na posição inicial, uma vez que foi a única subtarefa em que os três grupos participaram.

Uma hipótese que emerge desses resultados é a de que o contato crescente com a linguagem escrita, pelo ingresso no primeiro ano do ensino fundamental, possa estar beneficiando as crianças de seis anos ou mais, ou seja, as mesmas estão em fase de aquisição da habilidade de consciência fonêmica ${ }^{(20)}$, o que explica os achados deste estudo. Em nossa amostra, alguns sujeitos de seis anos e todos os sujeitos de sete anos haviam sido expostos à escrita.

Fatores como idade ${ }^{(5,19-21)}$ e alfabetização ${ }^{(19,22-24)}$ são apontados por diversos pesquisadores como capazes de refletir as habilidades em consciência fonológica. À medida que aumenta a idade e o contato com a língua escrita, estes autores observaram melhora nas habilidades em consciência fonológica. Isso ocorreu tanto em crianças com desvio fonológico quanto naquelas sem alterações.

No desempenho em vocabulário expressivo, um estudo

Tabela 4. Diferenças significativas na comparação dos desempenhos entre idades

\begin{tabular}{lcccccccccc}
\hline \multirow{2}{*}{ Variável } & \multicolumn{3}{c}{5 anos } & \multicolumn{3}{c}{6 anos } & \multicolumn{3}{c}{7 anos } \\
\cline { 2 - 10 } Valor de p \\
\hline Meios de transporte & $\mathrm{n}$ & Média & $\mathrm{DP}$ & $\mathrm{n}$ & Média & $\mathrm{DP}$ & $\mathrm{n}$ & Média & DP \\
Móveis e utensílios & 10 & 65,60 & 17,24 & 10 & 81,00 & 11,83 & 4 & 82,00 & 7,35 & $0,038^{*}$ \\
Locais & 10 & 64,10 & 18,14 & 10 & 76,10 & 6,23 & 4 & 77,00 & 2,31 & $0,028^{*}$ \\
T2 & 10 & 28,40 & 23,07 & 10 & 57,50 & 18,63 & 4 & 66,50 & 23,57 & $0,011^{*}$ \\
T5 trissílabas & 10 & 55,00 & 18,41 & 10 & 83,00 & 11,60 & 4 & 90,00 & 14,14 & $0,002^{*}$ \\
T5 quadrissílabas & 10 & 30,00 & 34,32 & 10 & 97,00 & 6,75 & 4 & 95,00 & 10,00 & $0,040^{*}$ \\
T6 inicial & 10 & 33,00 & 41,58 & 10 & 88,00 & 16,87 & 4 & 87,50 & 9,57 & $0,027^{*}$ \\
T6 final & 10 & 22,00 & 12,52 & 10 & 60,00 & 33,67 & 4 & 87,50 & 9,57 & $0,017^{*}$ \\
T6medial & 10 & 20,00 & 21,08 & 10 & 54,00 & 30,26 & 4 & 50,00 & 14,14 & $0,020^{*}$ \\
T9 inicial & 10 & 20,00 & 18,86 & 10 & 52,00 & 18,74 & 4 & 77,50 & 26,30 & $0,001^{*}$ \\
\hline
\end{tabular}

* Valores significativos $(p \leq 0,05)$ - Teste de Kruskal-Wallis para comparação das variáveis entre três idades, e Teste de Mann-Whitney para duas idades

Legenda: $\mathrm{n}=$ número de sujeitos; $\mathrm{DP}$ = desvio-padrão; $\mathrm{T} 2$ = realismo nominal; $\mathrm{T} 5$ = segmentação silábica em palavras trissílabas e quadrissílabas; $\mathrm{T} 6=$ detecção de sílabas iguais em início, final e meio de palavras; $\mathrm{T} 9$ = detecção de fonemas iguais em início de palavras 
sobre crianças com alteração do desenvolvimento da linguagem, com idades entre três e cinco anos ${ }^{(10)}$, também encontrou evolução positiva, com a idade, em uma prova de verificação do vocabulário expressivo. $\mathrm{O}$ fato de o desvio fonológico ter sido incluído entre as alterações de vocabulário dessas crianças nos autoriza a utilizar seus resultados para corroborar os achados desta pesquisa.

Os resultados do presente estudo evidenciaram que, quanto menor a idade dos sujeitos, maior o número de correlações significativas e positivas entre vocabulário expressivo e consciência fonológica nos níveis relacionados às maiores unidades da fala, como a consciência de palavras, de rimas e de sílabas. Tais resultados poderiam se justificar pelo fato de o aprendizado do vocabulário expressivo estar intimamente relacionado ao processamento de unidades de fala maiores e mais concretas para as crianças, como a consciência de palavras, de rimas e de sílabas. Verificou-se ainda que, quanto maior a idade, melhor o desempenho nestas duas habilidades.

Porém, levando-se em consideração as correlações positivas, observou-se que elas são maiores quando as crianças são mais novas, ou seja, a influência de uma habilidade sobre outra é mais forte quando as crianças são mais jovens e estas habilidades estão em desenvolvimento. À medida que as crianças se desenvolvem, estas habilidades vão se tornando mais independentes. Estas constatações poderiam se justificar pelo conhecimento prévio adquirido pela criança com mais idade, e pela influência da linguagem escrita. As crianças com mais idade passariam a ter contato maior com os conceitos de grafema e fonema (e maior consciência fonológica), e não prestariam tanta atenção a conhecimentos mais automáticos (como o vocabulário).

Segundo um estudo ${ }^{(2)}$, a relação entre desenvolvimento fonológico e desenvolvimento lexical inicial é tão estreita que não é possível separar estes dois aspectos nos primeiros estágios da aquisição da linguagem. Assim sendo, crianças com atraso de fala, mas com vocabulário mais amplo, têm um sistema fonológico mais complexo do que aquelas com poucas palavras armazenadas no léxico.

Os achados da presente pesquisa concordam com as constatações de outros pesquisadores ${ }^{(16,25)}$ quanto à interrelação entre consciência fonológica, vocabulário e desvios fonológicos, e que déficits em uma destas habilidades podem prejudicar o desempenho das outras.

Embora apresente limitações, como o número reduzido de sujeitos, tais achados assumem importância clínica fonoaudiológica, no atendimento a crianças com desvio fonológico. Tanto a detecção precoce de alterações nas habilidades em consciência fonológica e vocabulário, quanto o direcionamento adequado de condutas terapêuticas são facilitados quando se conta com referências norteadoras. Ao esclarecer estas relações, torna-se de fundamental relevância a construção de um programa de intervenção para a ampliação do vocabulário e das habilidades de consciência fonológica, os quais, aplicados de forma integrada à terapia fonoaudiológica podem reduzir o tempo de intervenção e evitar problemas futuros na aquisição da linguagem.

\section{CONCLUSÃO}

Pode-se concluir que há correlação entre algumas habilidades em consciência fonológica e vocabulário expressivo em crianças com desvio fonológico, nas idades de 5 a 7 anos.

Os desempenhos nas habilidades de consciência fonológica e vocabulário expressivo melhoraram com o aumento da idade dos sujeitos. Porém, levando-se em consideração as correlações, há maior número de correlações positivas entre consciência fonológica e vocabulário quando as crianças são mais novas, ou seja, a influência mútua das habilidades é mais forte quando as crianças são mais jovens e estas habilidades estão em desenvolvimento. A medida que aumenta a idade das crianças, estas habilidades vão se tornando mais independentes, e diminui o número de correlações.

Os níveis de consciência fonológica positivamente correlacionados aos escores do vocabulário expressivo foram, em maior número, aqueles relativos às unidades de fala maiores, como palavras, rimas e sílabas, o que poderia se justificar pelo fato de o aprendizado do vocabulário expressivo estar intimamente atrelado ao processamento de unidades de fala maiores e mais concretas para as crianças.

\begin{abstract}
Purpose: To investigate the correlation between the performance of children with phonological disorder in tests of expressive vocabulary and phonological awareness, and to analyze the influence of age. Methods: Participants were 24 children between 5 and 7 years old, diagnosed with phonological disorder and divided into three groups according to age range. These subjects were assessed in their phonological awareness and expressive vocabulary abilities. Data from the groups were statistically analyzed in order to verify the correlation between the performances on both tests, and to compare numerical variables between age groups. Results: The 5-year-old group presented 18 significant correlations between phonological awareness sub-tasks and expressive vocabulary semantic fields. Seventeen of these correlations were positive and one was negative. The 6-year-old group presented ten correlations, nine positive and one negative. The 7-year-old group presented 11 correlations, six negative and five positive. In both tests, higher scores were reached by older subjects. Conclusion: A correlation was found between some phonological awareness abilities and the expressive vocabulary of the children with phonological disorder in this study, in different ages. Performance in both tasks improved with age.
\end{abstract}

Keywords: Language tests; Vocabulary; Semantics; Child language; Language development; Child 


\section{REFERÊNCIAS}

1. Yavas M, Hernandorena CLM, Lamprecht RR. Avaliação fonológica da criança: reeducação e terapia. Porto Alegre: Artes Médicas; 1992.

2. Stoel-Gammon C. Normal and disordered phonology in two-year-olds. Top Lang Disord. 1991;11(4):21-32.

3. Mota HB. Fonologia: intervenção. In: Ferreira LP, Befi-Lopes DM, Limongi SCO, organizadores. Tratado de fonoaudiologia. São Paulo: Roca; 2004. p. 772-86.

4. Freitas GCM. Sobre a consciência fonológica. In: Lamprecht RR. Aquisição fonológica do português: perfil de desenvolvimento e subsídios para terapia. Porto Alegre: Artmed; 2004. p. 179-92.

5. Cielo CA. Habilidades em consciência fonológica em crianças de 4 a 8 anos de idade. Pró-Fono. 2002;14(3):301-12.

6. Marchetti PT, Mezzomo CL, Cielo CA. Desempenho em consciência silábica e fonêmica em crianças com desenvolvimento de fala normal e desviante. Rev CEFAC. 2010;12(1):12-20.

7. Mota HB, Melo Filha MGC, Lasch SS. A consciência fonológica e o desempenho na escrita sob ditado de crianças com desvio fonológico após realização de terapia fonoaudiológica. Rev CEFAC. 2007;9(4):47782.

8. Spíndola RA, Payão LMC, Bandini HHM. Abordagem fonoaudiológica em desvios fonológicos fundamentada na hierarquia dos traços distintivos e na consciência fonológica. Rev CEFAC. 2007; 9(2):180-9.

9. Bassano D, Maillochon I, Eme E. Developmental changes and variability in the early lexicon: a study of French children's naturalistic productions. J Child Lang. 1998;25(3):493-531.

10. Befi-Lopes DM, Gândara JP, Felisbino FS. Categorização semântica e aquisição lexical: desempenho de crianças com alteração do desenvolvimento da linguagem. Rev CEFAC. 2006;8(2):155-61.

11. Hage SRV, Pereira MB. Desempenho de crianças com desenvolvimento típico de linguagem em prova de vocabulário expressivo. Rev CEFAC. 2006;8(4):419-28.

12. Cycowicz YM, Friedman D, Rothstein M, Snodgrass JG. Picture naming by young children: norms for name agreement, familiarity, and visual complexity. J Exp Child Psychol. 1997;65(2):171-237.

13. Athayde ML, Carvalho Q, Mota HB. Vocabulário expressivo de crianças com diferentes níveis de gravidade de desvio fonológico. Rev CEFAC. 2009;11(Supl 2):161-8.
14. Gershkoff-Stowe L, Hahn ER. Fast mapping skills in the developing lexicon. J Speech Lang Hear Res. 2007;50(3):682-97.

15. Tyler AA. Assessing stimulability in toddlers. J Commun Disord. 1996;29(4):279-97.

16. McDowel KD, Lonigan CJ, Goldstein H. Relations among socioeconomic status, age, and predictors of phonological awareness. J Speech Lang Hear Res. 2007;50(4):1079-92.

17. Befi-Lopes DM. Vocabulário. In: Andrade CRF, Befi-Lopes DM, Fernandes FDM, Wertzner HF. ABFW: teste de linguagem infantil nas áreas de fonologia, vocabulário, fluência e pragmática. Barueri: PróFono; 2000. cap. 2.

18. Cielo CA. Habilidades em consciência fonológica em crianças de 4 a 8 anos de idade [tese]. Porto Alegre: Faculdade de Letras da Pontifícia Universidade Católica do Rio Grande do Sul; 2001.

19. Cielo CA. Avaliação de habilidades em consciência fonológica. J Bras Fonoaudiol. 2003;4(16):163-74.

20. Souza APR, Pagliarin KC, Ceron MI, Deuschle VP, Keske-Soares M. Desempenho por tarefa em consciência fonológica: gênero, idade e gravidade do desvio fonológico. Rev CEFAC. 2009;11(4):571-8.

21. Vieira MG, Mota HB, Keske-Soares M. Relação entre idade, grau de severidade do desvio fonológico e consciência fonológica. Rev Soc Bras Fonoaudiol. 2004;9(3):144-50.

22. Ettore B, Mangueira ASC, Dias BDG, Teixeira JB, Nemr K. Relação entre consciência fonológica e os níveis de escrita de escolares da $1^{\text {a }}$ série do ensino fundamental de escola pública do município de Porto Real - RJ. Rev CEFAC. 2008;10(2):149-57.

23. Cárnio MS, Santos D. Evolução da consciência fonológica em alunos de ensino fundamental. Pró-Fono. 2005;17(2):195-200.

24. Zuanetti PA, Schneck APC, Manfredi AKS. Consciência fonológica e desempenho escolar. Rev CEFAC. 2008;10(2):168-74.

25. Rvachew S, Chiang PY, Evans N. Characteristics of speech errors produced by children with and without delayed phonological awareness skills. Lang Speech Hear Serv Sch. 2007;38(1):60-71. 